RESEARCH ARTICLE

\title{
Learning accountability literacies in educational workplaces: situated learning and processes of commodification
}

\author{
Karin Tusting* ${ }^{\text {a }}$ \\ a Department of Linguistics and English Language, Lancaster University, Lancaster, UK
}

(Received 15 February 2011; final version received 30 July 2011.)

\begin{abstract}
Literacies are always learned in particular social places and spaces, and the nature of a site shapes the experiences people have of learning literacies there. This paper considers the experiences of staff in two contrasting workplaces: an early years centre, and an adult education college. Both are educational workplaces, and staff are engaged in extensive literacy practices relating to recording and accountability, which they colloquially term 'the paperwork'. In both sites, this paperwork is a source of struggle. However, closer analysis based on interviews and observations showed that there were significant differences between people's experiences of learning accountability paperwork practices in the two sites. The paper identifies the key characteristics of these sites which seemed to foster or discourage the development of 'mastery' or 'skilled knowledgeability', drawing on situated learning theory. These site-specific characteristics are related to the broader processes of commodification of education within which the sites are situated.
\end{abstract}

Keywords: Workplace literacy; paperwork practices; commodification; skilled knowledgeability; situated learning; mastery

\footnotetext{
* Email: k.tusting@lancaster.ac.uk
} 


\section{Learning accountability literacies in educational workplaces: situated learning and processes of commodification}

\section{Accountability literacies and the commodification of education}

In recent years, increasing levels of "accountability" have been introduced in a range of settings, particularly in publicly-funded arenas such as education and healthcare.

Accountability systems are systems for the production of evidence which can be made available for checking and auditing (Power 1997) in order to verify that work has been carried out in an appropriate manner, that progress is being achieved, and that money (particularly taxpayer money) has been spent as efficiently as possible. Such accounts are normally written ones (see eg Folinsbee 2004), and are therefore associated with a range of what I will call in this paper "accountability literacies", that is, the reading and, particularly, writing practices associated with accountability systems. This paper addresses the processes by means of which staff in two educational workplaces learn such accountability literacies, and the influence of the site in which they work on these learning processes.

Education is subject to demands from policy frameworks, inspection authorities, examining boards, funding agencies, and various other authorities. All of these have different reporting demands which staff and managers in educational workplaces have to fulfil. Accountability paperwork demands are rigidly prescribed, and staff have to learn to conform to particular discourses and genres. There is a burgeoning literature which explores and challenges the consequences (often unintended) of such heightened levels of accountability in educational settings (eg Cuban 2009, Valli and Buese 2007, Hanushek and Raymond 2005). Studies in schools (Troman, 2000; Williams, Corbin, \& McNamara, 2007) and in further education (Hamilton, 2009) have identified the stresses and contradictions associated with these paperwork demands. Moves to increase accountability in education are normally associated with a policy discourse of improving standards (Taubman 2009). However, it has been argued that such demands are better interpreted as being part of a broader set of social structural changes introducing commodification in education (Apple, 2005; Ball, 2005; Fairclough, 2003).

Commodification refers to processes which transform things (goods, services, labour power) into commodities, that is, entities which have economic exchange value and can therefore be traded in a market. One of the characteristics of late modernity is the resultant expansion of the market to areas previously considered non-marketable (Chouliaraki and Fairclough 1999). The commodification of education is characterised by attempts to transform the complex and unpredictable social processes involved in teaching and learning into 'products' with exchange value which can be used for comparison and competition. This is achieved through processes such as the introduction of centralised curricula and standards, which define what counts as legitimate knowledge or learning; standardised testing against these standards; and comparison of test results between institutions. This is often associated with tight controls over the ways such curricula are being 'delivered' in the classroom, such as for instance the National Literacy Strategy which was introduced to standardise literacy teaching in the UK in the late 1990s (Machin \& McNally, 2008). Teaching quality is assessed in terms of compliance with externally prescribed models, both through internal performance appraisals and external inspection regimes. Accountability is achieved using techniques from accounting and management such as audits (Power, 1997) or Balanced Score Cards (Lawrence \& Sharma, 2002) to process the measures produced in various ways. Such metrics are used to produce league tables, place institutions in competition against one another, and assess performance against externally set targets. 


\section{K. Tusting}

The nature of 'professionalism' in the workforce often changes at the same time (Gleeson, Davies, \& Wheeler, 2005; Shain \& Gleeson, 1999), with 'professionalisation of the workforce' being equated with making sure that teachers have qualifications equivalent to a particular level, or indeed introducing new types of qualifications associated with centralised curricula, as happened for instance with the introduction of core curriculum training related to the Skills for Life strategy for adult literacy, numeracy and ESOL provision in England (DfEE, 2001; Lucas, Casey, \& Giannakaki, 2004; see also Hamilton, this issue). Ball (2005) suggests that such a system aims to produce a 'post-professional' class of teachers, more responsive to external requirements and specified targets than to their students, armed with formulaic methods to achieve these goals, where 'professionalism' indexes the willingness and ability to adapt to policy, rather than to student needs.

This paper describes the experiences of staff in two contrasting educational institutions dealing with accountability paperwork, exploring how characteristics of the two sites (situated differently within such commodification processes) shape the processes of learning accountability literacies.

\section{Mastery and situated learning}

Work in situated learning and distributed cognition demonstrates the importance of the context within which people learn new practices. Early accounts of situated cognition include Scribner and Cole's (1981) practice account of literacy, Rogoff and Lave's (1984) study of everyday cognition, and Lave's (1988) work on mathematical cognition in everyday life. Brown, Collins and Duguid (1989) drew on this work to argue that learning cannot be interpreted in isolation from the context in which it is developed; rather, knowledge is produced through activity in situations. Further work by Lave (1991) and colleagues developed an understanding of learning not as a process of internalization of knowledge by an individual, but of engagement in the activities of a sustained community of practice. From this perspective, becoming a member of the community and becoming "knowledgeably skilful” are essentially the same process (a perspective which has been developed extensively, see especially Lave and Wenger (1991), Wenger (1998), Barton and Tusting (2005)). This is an understanding of learning as social practice in the world, with the development of "skilled knowledgeability" arising through participation.

Despite her focus on the situatedness of learning, Lave (1991) objects to a purely local interpretive view. She points out that broader social structural relations shape the nature of communities of practice, and that these are not necessarily immediately accessible. Her critique of learning in contemporary workplaces in schools relates this to processes of commodification of knowledge, arguing that knowledgeable skill developed through community activity is devalued, making it hard for meaningful learning to take place in these settings. She suggests that diminishing possibilities for developing identities of mastery are part and parcel of the essentially alienated condition of contemporary life.

This paper will compare the extent to which staff engaging in accountability literacies in the two contrasting educational workplaces expressed a sense of mastery or 'skilled knowledgeability' of these practices, interpreting this in relation to specific characteristics of the sites which encourage mastery of or alienation from workplace literacy practices. 


\section{Two sites of learning accountability literacies}

The research reported here was carried out in two educational workplaces: an early years site providing care for young children, and an adult education college ${ }^{1}$. I worked closely with 20 members of staff across the two sites. I observed their workplaces and practices, keeping detailed field notes, including accounts of informal discussions about paperwork which we had during the observations. I carried out repeated audiorecorded interviews, asking them initially to describe the paperwork practices that they engaged in during work and discussing the impact of these on their experiences. I then worked with them to design formats which they used to 'log' the paperwork they encountered over a few days. I carried out further audiorecorded interviews focusing specifically on these logs, asking participants to describe in more detail the paperwork practices they had noted and explain how these related to the other things which were going on in their lives. The data was analysed in detail, coding for content and theme to enable the identification of patterns in the data and also unexpected contradictions, using the software programme Atlas-ti to facilitate and record the analytic process $^{2}$.

In both sites, paperwork served a range of purposes, including planning, recording and evaluating activities and learning. In both, the nature of the paperwork was shaped by policy and funding structures, mediated through systems of inspection, and constructed by local management. However, beyond these broad similarities, many aspects of the two sites were different.

\section{Early years centre}

The early years site was a nursery based on the site of a large public sector employer, catering for nearly 200 children aged between 3 months and 5 years. The paperwork demands faced by frontline staff were essentially driven by the demands of national childcare frameworks. At the time of the fieldwork (2008), these were the (non-statutory) Birth to Three Matters framework for younger children (DfES, 2002), and the statutory Foundation Stage for

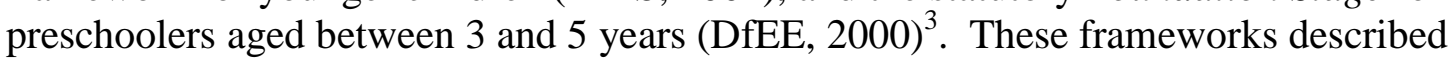
several areas of child development which children's activities were expected to support.

Nurseries were obliged to fulfil the demands of the frameworks, but were free to develop their own mechanisms for doing this. The centre management played a key role in designing a system which mediated these requirements. Short written observations of behaviour were written about each child on a regular basis, referenced against the relevant sections of the framework document. 'Next steps' were then planned for provision of future play activities and resources. A full-time member of staff was expected to produce ten observations a week. Once a week, all the observations produced by staff in one room were collated and formed the basis of planning for the following week's activities.

Compliance with these demands was established through regular checking by the management of the centre, including 'audits' carried out on by the centre managers on a monthly basis to verify in each room that all the procedures (including accountability paperwork, but also health and safety requirements and other mandated practices) were being followed correctly. These room audits were done on a competitive basis, and staff were aware that the team as a whole could face consequences if individual's paperwork was not completed. The centre was also subject to unannounced inspections from the national inspectorate Ofsted, which would include checking all the paperwork in detail and giving the centre an associated rating (with the power to impose sanctions from imposing more frequent 


\section{K. Tusting}

inspections to suspending registration of the establishment if provision was found to be unsatisfactory). All staff were very aware that Ofsted could turn up on the doorstep at any time without giving warning, so felt both internal and external pressure to keep up to date with paperwork at all times.

The linguistic form of the observations was tightly constrained. Staff were expected to label observations and planning with components of the framework, and to draw on and imitate the discourse of the framework document examples in their recording of children's behaviour. Observation forms specified space for the observation, relating it to the framework, and space for 'next steps'. In these descriptions, children's behaviour is explicitly related to the language and components of the frameworks. For instance, an observation of the behaviour of one 5 1/2 month old read" ${ }^{4}$ "I placed L. on the carpet nearby the mirror, he sat facing the mirror, I sat next to him and made funny faces; L. started smiling and making babbling noises. A. - A Skilful Communicator." The final clause is a reference to the particular section of the framework to which this observation is being related with this comment.

This observation > planning $>$ reporting cycle formed the structure for each room's activities each week, but by no means exhausted the paperwork practices staff were engaging in each day, which included the production of daily record sheets and longer-term 'records of achievement' for parents, health and safety monitoring information, displays for the walls, a central diary for each room containing date-specific information, accident records, medicine records, contact details forms, permission slips, medium term planning, and a register.

\section{Adult education college}

The paperwork system in the nursery was complex, and staff were faced with a wide range of demands. However, each member of staff was essentially dealing with the same complex set of paperwork requirements. This contrasts with the very varied situation of tutors at the other site, a medium-sized adult and community college providing courses in literacy and numeracy, ESOL, access courses, and a range of leisure and non-qualification part-time courses. I worked with a range of tutors from areas across the college, including community education, non-vocational, and learning support areas. The majority of these were employed on hourly-paid contracts, typical of a high proportion of staff in the adult education sector generally (Osborne and Sankey 2009), although two of them (Megan, a community literacy tutor, and Aidan, who had both a tutoring and a managing role) were employed full-time.

All tutors had to produce planning paperwork related to their teaching, to submit to the quality management at the college. This included course rationales, schemes of work, lesson plans, and individual learning plans for learners. Reporting paperwork included registers, achievement reports, course evaluations, test scores, and RARPA (Recognising and Recording Progress and Achievement) records of various kinds. Tutors also had to fulfil a range of different health and safety related demands, including risk assessments for many activities.

However, beyond these similarities almost every tutor I worked with had a different set of demands to fulfil, depending on their programme area, their role, and their particular responsibilities. For example, Megan's paperwork ${ }^{5}$, as a community practitioner who largely managed her own time, included receiving and processing assessment forms from tutors delivering NVQs (National Vocational Qualifications, a competence-based qualification related closely to workplace practices); keeping files for each individual she worked with; 
completing contact sheets, initial assessment, feedback sheets, enrolment forms, and paperwork related to Train to Gain, a Government programme funding workplace-based training provision;, keeping a register for any group work, and completing planning sheets. She also worked with ex-offenders following educational programmes through the Probation service, and for this work had to collect data on numbers of assessments and referrals, numbers of hours, attendance sheets, and community service paperwork. She had particular forms to fill in when her teaching was observed by quality management, and evaluations to complete after doing training. She was also responsible for submitting details of all her contact hours to the college management, supported by copies of record sheets signed by learners which she was expected to photocopy herself.

This is very different from the paperwork demands Tim faced as a learning support tutor, working one-to-one with students who needed support for their learning for various reasons. His paperwork consisted primarily in maintaining records associated with the students he was working with: a record of the learning taking place in each lesson, against specific learning goals drawn from their individual learning plans; supporting the student in completing any paperwork related to the class itself, such as their own record of work done at the end of a literacy class; carrying out assessments and completing the related assessment forms, in response referral forms from tutors; and completing pay claims with details of lessons attended and hours, supported by photocopies of every learning record form (which, again, Tim had to photocopy himself).

Specific approaches to recording and planning teaching were mandatory. College management provided formats for lesson plans and schemes of work which tutors were expected to use appropriately. The use of SMART targets (specific, measurable, achievable, reliable, time-bounded - an acronym from the world of management) was expected when framing learning goals. Such learning goals were to be marked on review forms as 'achieved' or 'not achieved', although this was not necessarily clear-cut; as Tim told me in discussing the learning record to be completed at the end of each course, they had to assess "has learning goal one been reached, yes or no. Now in discussing with tutors I sometimes say so do you think this learning goal has been achieved and they say, well - up to a point. But this is very yes or no oriented."

Paperwork was checked in a range of different ways. Line managers for the various programme areas in the college were responsible for ensuring that staff understood and complied with the various demands they were facing. The Management Information Service team would contact staff directly if they were not receiving the right kind of information for their records; this was particularly important where funding streams were dependent on particular information being passed on. The college also had a quality management team who observed teaching on a regular basis and checked that the associated paperwork had been completed correctly, requiring submission of schemes of work and session plans as part of their observation processes. Staff who fell short were assigned to a "mentoring" process with a member of the quality management team. The college were also subject to regular Ofsted inspections, though these were not unannounced as they were at the Early Years Centre.

\section{Different levels of mastery: Mastery or managing?}

While paperwork was an issue for staff in both sites, there was a significant difference in the way it was described in each. At the nursery, most staff - even those most negative about the paperwork - were confident in their mastery of the paperwork. While many of them still 


\section{K. Tusting}

expressed concern at the volume of observations they were expected to produce, their capacity to use the frameworks as required was not normally described with anxiety. It was more usual to find a description like Enid's, who told me that when the framework was introduced, she found it "a bit daunting", but that now, after all the repetition and practice they have had, "you just sort of reel it off"; she described herself as "fairly confident with it all” now. Libby enjoyed doing the planning, "now I've gotten into it. At first, it was not very nice to do, because you were always 'I hope I've done this right' and 'I hope everything's OK', but once you're familiar with it ...” She now described herself as being "at ease with it". Harriet, working with the pre-school foundation framework, said "I feel as though I know this. [...] Somebody will say something and you'll be able to say "Oh, that's in PSE [personal, social and emotional, an element of the framework]. You can even rhyme off the stepping stone.” In general, despite issues of overload, pressure and clashing priorities, staff seemed to express a sense of "knowledgeable skilfulness" in the actual process of using the frameworks and producing the paperwork.

The situation was rather different at the college. Whereas at the early years centre staff were more likely to talk about having moved from anxiety about these demands to confidence, staff at the college were more likely to describe a more ongoing process of managing and coping with the demands they were faced with. They were much less likely to use phrases associated with a discourse of easy mastery like 'reel it off'. For instance, Tim, describing the process of learning how to fill in the learning support forms appropriately for very different learners, told me that "You get used to it, the training is quite good but it's quite a challenge”. Megan described various strategies for keeping on top of the paperwork, including mind mapping to do lists, preparing one day at a time, and coming in for extra hours to catch up, but never seemed quite satisfied that she was managing this in the best way, reflecting on different possible approaches: "I know my colleague he comes in one day a week and does all his preparation then, perhaps that's what I should do", or wondering whether she should be in a job which involves this much paperwork: "it made me really think, why am I doing something that, I mean any job you did you'd have paper, but why am I doing specifically something that is so paper based and that's obviously not one of my strengths."

While Megan individualises the issue as being her own problem, almost all of the tutors I worked with, even those who described themselves as being organised and 'on top of' the paperwork, found it a challenge and had to constantly review and develop their strategies. Anna, a tutor who taught one day a week and spent at least another two working on the associated paperwork, had recently had a quality assessment which rated her as being exemplary in her compliance with the paperwork. She showed me her filing systems supremely well-organised - and told me, "I have to say that there are not all the documents that come out of college in here at all, a lot of them go in the bin as soon as I see them and I'm not being very good this term, even though I knew you were coming, a lot of them have gone in the bin. But I can't cope with them, I can't cope with any more.” Describing one particular demand, she told me, "this is something else that rattles me no end. We have to do a profile on each student and I have to say I am not getting on with it. I mean on top of all this recording this is the profile and I haven't done it you see.” She described the documentation requirements from the exam board she worked with as "horrific ... all these little bits that you have to do", and had many other examples of struggles with the various forms of paperwork she encountered. As a tutor who represented the most 'expert' end of coping with the paperwork, the strength of feeling she expressed about this was striking. 
In this paper, I will explore the factors in the two sites under study here which changed the nature of the learning processes in each. I will argue that three sets of factors made the development of 'mastery' or 'knowledgeable skilfulness' in dealing with the paperwork more or less likely: the resources available to people in the sites; the extent of integration of paperwork demands with other processes in the workplaces; and the extent of stability or change in each site.

\section{Factors shaping learning in the two sites}

\section{Resources for learning}

\section{Time and space}

Aspects of both time and space affected the learning processes in both of the sites described here. At the Early Years Centre, there was very little dedicated space and time available to engage in accountability-related literacy practices. Once a week, one member of staff in each room was designated 'team leader' and enough cover was provided for them to have a couple of hours 'planning' time in the staffroom. If they finished this planning quickly, the rest of the time could be used to catch up on the rest of their paperwork. Apart from this, paperwork was carried out on child-size tables and chairs, or leaning up on top of bookcases in the rooms, while remaining responsible for looking after the children, during the working day. While some parts of the day were quieter, it was usual for paperwork to be interrupted by the immediate demands of childcare many times, and for staff's attention to be 'split' between constant vigilance towards children's behaviour and safety, and completing the paperwork (Tusting, 2010).

However, carrying out writing in the rooms also had its advantages. Arrangements of space in the room were structured to support the task at hand. The rooms reflected the frameworks. Different areas of the room were associated with different aspects or components. Charts were on the walls immediately to hand, to quickly record information such as nappy changes as they happened, for easy transfer to the daily record sheets in a batch.

The nature of time in the rooms also supported staff's learning processes. While the events of each day were unpredictable, there was a routine structure, and it was possible in most rooms to develop habits such as predictable when the paperwork could be completed (for instance, in the nursery room while most of the children were sleeping). The paperwork that had to be completed each week was roughly the same, so the cyclical nature of time in the rooms supported the repetition of similar tasks. Larger one-off tasks, such as mediumterm planning and termly Individual Play Plans, tended to be more problematic.

At the adult and community college, the distribution of time and space was different. The nature of the space available to tutors for paperwork varied. Some tutors had management responsibilities and their own office space, and were working full-time or close to it. Most, though, were part-time. A staff room was available, and some staff worked in there between classes, but in practice, most paperwork was completed by most staff in their own homes.

The time cycle of paperwork here was different, too. Rather than a daily routine, some regular paperwork activities such as lesson plan, review and register were on a weekly basis. Many, such as course rationales, schemes of work and health and safety assessments 


\section{K. Tusting}

were on a termly basis. Staff also dealt with regular one-off requests. As Megan describes it, her rhythms of doing the paperwork varied greatly depending on the work required and her other commitments: "Thursday I came in and my desk was a mess, and I had all these files, so I stopped here [...] Monday I was supposed to be doing, starting a course and it's been cancelled, so Monday morning now, I have put it in my head. I haven’t got another appointment until 3.15 so I'm just going to go through all my files." Changing situations and requirements made it harder to get into a regular routine, making their work fragmented temporally, as well as spatially.

\section{Mediating artefacts}

At the Early Years Centre the use of the framework was supported by a wide range of mediating artefacts immediately available to people in the space in which they were writing. Each framework was supported by a range of mediating tools. The Birth to Three Matters Framework pack included a booklet, CD and video, a colourful poster identifying and illustrating the aspects and components, and sixteen 'component cards'. These posters were displayed on the walls of each room, and a set of the cards was kept close to where the staff did their writing. Displays produced by children and even different areas in the rooms were all labelled with aspects and components of the framework. Similarly, the colour-coded stepping stones of the Foundation Stage were on display in various ways throughout the preschool rooms, and folders of detailed guidance were easily available.

Staff relied on these artefacts when writing. In paperwork logs that they kept for this research, 'Completing observations' was consistently accompanied by 'Consulting Birth to Three / Framework support material'. The immediate presence of support material in the environment provides readily-accessible framing categories. Enid described the process as follows:

On our back wall we've got all the Birth to Three different categories stuck up on the wall, so you've got your skilful communicator, your strong child, your competent learner [names of different sections of the framework], and each one is separated into the different categories, so that's there in front of you [...] We also do have cards which are the same as what's on the wall, and you can take them off and put them sat with you if you want and to help you, if you're struggling for something and you can't think what you'd like to categorise in what they've been doing, you've got that there to look back on and it just gives you a little help.

When the framework was first introduced, she said that figuring out how to move from what was written on the cards to what they were writing in the observations was "really hard, because you had to look at the component and find the aspect, or find the aspect and then get the component, and that just took such a long time.” However, she now felt very confident with using the framework, though still referred to the cards each day. Similarly, Katie referred to the Birth to Three documents "all the time. We've got them displayed on the wall in the room. [...] Because you look at it so much, it's in your head all the time, but you still need to refer, to check that whatever you're observing a child doing, it fits into that section.”

In contrast to the Early Years Centre, partly related to the fact that everyone had different sets of demands, few mediational tools were on display at the adult and community college. While staff at the Early Years Centre would be completing paperwork in the same space each day, drawing on mediating artefacts which were always available in that environment to support this work, staff at the college had much less ownership of the spaces 
they worked in. Teaching often happened in different rooms, mostly not their own, and even where the same space was always used (for instance for some of the craft classes), it normally had to be set up each time for the particular class that would be held there. Supports for carrying out paperwork were therefore not immediately available in the space in the same way, and people did not complete their paperwork in the same way, by looking at and drawing on written examples in the immediate environment.

\section{Other people}

Other people are an important resource for learning. At the early years centre, staff tended to work in the same room, with the same people, for extended periods. Day in, day out, the same group were working closely together, engaged in similar tasks, facing almost identical paperwork demands. Staff in this site were much more likely to talk about divisions of labour in dealing with paperwork demands, producing planning as a team, and supporting one another in the learning process. Returning to Enid and Louise's discussion of the new framework, Louise told me that it wasn't until Enid talked her through it that it started to make sense: "It was just different language, and Enid knew me well enough to interpret it and say look, you do this, just write it down under that.” This is not simply a matter of being able to explain the task itself; it is because Enid knows Louise well, from a long history of working with her on a daily basis, that she is able to interpret the framework in a way that Louise can easily grasp. This process also helped Enid, who said that "when you're explaining to someone, you're getting it a bit more [...] the more you go through things, the more you take it in yourself."

At the adult and community college, tutors were divided into programme areas and had regular meetings with their line managers, but many worked alone for most of the time. There were not, therefore, the sorts of opportunities for informal exchange and learning from each others' practices that were a matter of course at the Early Years Centre. Even when they were completing their paperwork in the staff room, they were not necessarily there at the same time as other staff working in similar areas or dealing with similar requirements another reflection of the hourly-paid part-time nature of the work many of them were doing, and the multiplicity and variety of demands that tutors were faced with.

\section{Resources, situated learning and commodification}

Identification of the important resources for learning in these sites confirms insights from situated learning. Where the time and space available to engage in the activity are constrained, attaining mastery through participation will be more difficult. As Kirsh (1995) identifies, informed by work on distributed cognition (Hutchins, 1995), spatial structurings of the environment can support the development of expertise, where the environment is prestructured to support the task at hand - in the case of the early years centre, for instance, by the ready availability of mediating artefacts on the walls close to where writing took place. Similarly, Brown, Collins and Duguid (1989) demonstrate the importance of mediating resources in the environment supporting each occasion learning is used in activity. Lave (1991) argues that the availability of such resources for cognition in the environment supports the development of skilled knowledgeability.

Other people are clearly a crucial resource, since without people to engage in activity with, co-development of learning and membership of a community of practice is not possible. As Lave and Wenger (1991) argue, learning is co-participation, therefore reduced opportunities for participation in activity with others implies that development of mastery 


\section{K. Tusting}

will be less likely. They argue that much learning, and failure to learn, can be accounted for by the underlying relations of participation in the community in which this learning is taking place.

The availability or otherwise of such resources for learning to complete the paperwork is directly influenced by the processes of commodification outlined above. Pressure to produce commodified representations of teaching and learning for monitoring and audit increases the volume of paperwork that people are dealing with, and hence decreases the time available for dealing with it. This affects both sites here. Pressures to maximise the 'efficient' use of human resources, managed by the use of hourly temporary contracts at adult education colleges, also minimise the time available for the completion of paperwork. Fragmentation of the teaching workforce's time in this way leads to fewer opportunities to learn from each other, even simply by chatting about demands in the staffroom. Similarly, pressures to increase 'efficiency' have led to the delegation of tasks which used to be for administrative staff to tutors (for instance, Megan and Tim having to do her own photocopying as they submit time claims), which again increases the volume of tasks needing to be done and reduces the time available for each one. On the other hand, the presence of mediating artefacts in the immediate environment does support mastery learning, and these are also evidence of commodification through the introduction of the centralised curriculum.

\section{Stability and change over time}

The second factor influencing mastery of paperwork demands was the nature of change in each site. Three years before this research, the nursery had introduced the Birth to Three Matters framework with the younger children. The pre-school rooms had been following the statutory Foundation Stage curriculum guidance since 2000, so staff who had worked in these rooms were familiar with the principles of observations and planning. Staff who had always worked with the younger children, however, found this a new approach. Although three years had passed since the introduction of the framework, for some members of staff the process of learning the new frameworks was still very fresh. The introduction of a new system had led to feelings, for some, of being swamped by everything they were having to learn at once.

However, the underlying framework and demands remained relatively stable (notwithstanding some ongoing minor changes, such as additional health and safety records). After a couple of months of using the system, developing routines and habits, with support from managers and colleagues, most expressed confidence with the system, describing it with phrases like 'second nature' or 'just what we do' signalling 'skilled knowledgeability' as described above. Jessica found the introduction of Birth to Three very hard: "because it's so different, it was having to adapt the way you have been working through a whole different system [...] all the information coming in, it took a lot of time to break down." However, "once it all clicked in, then it started to get easier. Once we started to actually do Birth to Three, then it became easier to know what it all meant, than when you were reading through it." Now she likes it: "It's hard work to fit it all in. But you can see how it does fit in. How it does help you."

Nicola, Louise and Enid's co-constructed description of the learning process was similar: 
NI: The more you do it, the quicker you get, just listing [unclear] the different aspects and everything. Now we know them ...

EN: ... we can reel them off like that, you know, what it is.

NI: But to begin with, it was a case of oh, what does that come under, so you'd be looking and you'd be looking and by the time you'd found what you wanted, it could have been like five minutes down the line, you know, probably ...

LO: ... yeah, and you'd have to read through the whole thing.

When the new system was introduced, people experienced overwhelm; but through repeated engagement in learning through doing, within a relatively stable system, they developed more confidence and a sense of ease in its use.

At the college, on the other hand, changing requirements were a constant feature, with small changes happening at least termly and often more frequently, increasing the sense people described of fragmentation or incoherence in the demands they were facing. Staying on top of these was difficult, particularly where staff were expected to use what they described as a 'new language' to complete their paperwork demands, such as being obliged to draw on the managerialist discourse of 'SMART' targets. John, another learning support tutor, showed that mastery of this language had yet to be achieved: “They're supposed to be SMART targets. [...] Something Measurable, yeah, I can’t remember ... Reasonable, Measurable, Attainable, something.” Requirements changed frequently, and were not always accompanied by training at the time the change happened. Tim described a change in the learning support form which he had yet to understand: "The new thing on the forms this year is support levels one, two, three, four and five which are detailed at the bottom here, now that's something I've meant to ask my supervisor about actually. Because I've got five different jobs at the moment, I haven't taken the chance." Since repetition contributes to the development of skilled knowledgeability, frequent change makes the achievement of mastery much more difficult.

\section{Change, situated learning and commodification}

The situated learning perspective suggests that mastery is achieved through repeated activity in a community of practice. Constant change therefore mitigates against the development of easy mastery. Brown, Collins and Duguid (1989) suggest that concepts evolve with each occasion of use, becoming more 'densely textured' with each repetition of the activity. Each time a conceptual tool is used through engaging in activity, a richer understanding is built both of the tool and of the world within which it is used. They state that developing "indexical representations" of a task through repeated engagement may increase the efficiency with which subsequent similar tasks are engaged with, but that this only works if the part of the environment structuring the representations remains the same.

Of course, change is a constant feature of social life. There is always conflict between continuity of practice and change, not least as newcomers become oldtimers (Lave \& Wenger, 1991). But having said that, there comes a point where change makes continuity much more difficult, and where the rich implicit understandings of a concept built up through time are too removed from the new practice to inform it. The question is the nature and extent of change. In a situation where there is constant change, in requirements, in work 


\section{K. Tusting}

practices, or in the make-up of teams, repetition of practices within a community becomes impossible.

The sorts of incremental changes described here are associated with particular aspects of processes of commodification of education, particularly the imposition of centralised changes irrespective of local rhythms. The multiple funding streams of adult and community education also lead to fragmented and changing paperwork demands.

\section{Integration or disjuncture}

A further aspect of the practices in the two sites which had an impact on learning was the extent to which paperwork demands were, or were not, integrated; firstly as a coherent system in themselves, and secondly with other work practices. Adopting the perspective that learning and activity are always part of the same process, it is not surprising that problems arise when the paperwork and other aspects of work are not closely connected, and where learning paperwork practices becomes a very different process from the activity itself.

\section{Integrated vs. multiple systems}

At the early years centre, most workplace literacy activities - observations, achievement books, planning, displays - were related in some way to the two overall frameworks within which the nursery was operating. At the college, on the other hand, courses and activities were funded through different funding streams, many of which had their own requirements. All these demands had to be fulfilled in specific formats, which varied depending on the source of the demand (college, county council, Learning and Skills council (the body responsible for distributing Government funding), examination or qualification body, community partner). All were expected to be in particular formats, and to use appropriate language. The different demands of these multiple systems were, to an extent, mediated by college management at various levels, who produced and passed on the various forms which tutors were expected to complete. Nevertheless, this variety meant that nearly every tutor participating in this research had a different set of paperwork demands to fulfil, in comparison to the single integrated system which every member of childcare staff was dealing with at the early years centre.

These multiple sources and reasons for the paperwork demands meant that it was common for staff to refer to paperwork demands as coming from an unspecified 'they', which could on examination be seen to refer to local quality management, information management, the county council, a funding body, an exam board, Ofsted, or some combination of the above. This multiplicity also led to frequent repetition, with tutors being asked to complete the same information on different forms, as Anna, a craft tutor, described: "The same kind of recording that you do for City \& Guilds [the exam board she was working with] you've generally got to do for college as well. So it's doubled.” She was one among many tutors who frequently encountered demands to provide the same information on different forms, and found this repetition infuriating.

\section{Paperwork and work}

At the early years centre, close integration of observations with planning means that people's writing tasks were clearly directly related to their everyday actions in the workplace. Descriptions of behaviours served both as a record and as a resource for planning activities. Observations, records and planning formed a tightly-linked intertextual series, in which the 
purposes of writing the observations were quite clear. Tensions were generated where 'stepping back' to write an observation clashed with what staff saw as their primary purpose, interacting with the children, and where the volume of observations required became difficult to manage. Nevertheless, most staff felt that the overall system of observations and planning did support them in their work activities.

At the college, staff were more likely to talk about experiencing active conflicts between 'the job' and 'the paperwork'. Particular problems arose when the paperwork was seen as actively clashing with the tutor's teaching goals; for instance, where they were required to assess achievement in different terms from the achievements they felt were most significant for their students, or where the format mandated by the lesson plan did not reflect their teaching approach. Dolly and Muriel, both of whom taught craft subjects, described the difficulty of producing a scheme of work for the term and a timed lesson plan in advance, when the class was being run on a responsive workshop basis and students chose different options as the term went on.

One common strategy for dealing with this was staff inventing paperwork to meet their own purposes, alongside the college's mandated formats. Megan, for instance, produced additional feedback forms for the learners she was working with through the Probation service, to provide a more supportive basis for a pedagogical discussion: "Originally I did this [feedback sheet] for Probation, because Probation were just awful, just giving them the score. Well what does that mean, an E3 or an E2 [levels of achievement in literacy or numeracy - these are "entry level"], or what does that mean to the individual? It doesn't mean anything. So I did this feedback sheet because I like to put down people's strengths, so even if they get a really low level of literacy here, at least we can talk about what they are good at.” Production of such supplementary paperwork for pedagogical purposes was common, but had a knock-on effect in increasing the volume of paperwork tutors were dealing with.

\section{Paperwork and professional identities}

The third aspect of 'integration' which had a significant impact on people's responses was whether paperwork demands were consonant with their professional identities. At the Early Years Centre, 'doing a good job' and being a competent childcare practitioner meant, in part, achieving what management asked. It was seen as legitimate for management to interpret policy requirements and to make recording demands on people. In the adult and community college, tutors generally had a history of working relatively autonomously as individuals planning their own lessons in their own formats, for example. Many tutors felt this autonomy had been eroded, as more and more of the paperwork they were doing was expected to be in particular, prescribed formats. They felt that trust in their professional capacities to do the job was being challenged, particularly where paperwork organized their practices to align with a centrally-prescribed curriculum. As Aiden summarised, "The whole thing seems to have been reduced to some kind of paperwork exercise. I think you could almost not teach a lesson, and just present all the course files. [...] It's all about justifying what we do and accounting for what we do. So, in a sense, I think it breeds animosity, that we're not trusted to get on, we don't have any sort of professional integrity to get on with what we're trained to do."

Most tutors at the college were on fractional or hourly-paid contracts and felt their employment was insecure, despite the fact that many were highly educated and experienced. While staff saw it as reasonable to complete some paperwork at home, recognition of the time 


\section{K. Tusting}

spent on this in their pay was an issue. In principle, tutors' hourly rate included time for preparation; but as the volume of paperwork increased, their hourly rate did not. This was particularly hard for tutors with more than one job, and / or who had extensive family or caring commitments. As Tim explained, “That's one of the factors that I think is a feature of college that although the people making up the forms have nine to five day jobs here, [for] the people on the frontline it's one of a range of things in their life, most of the thirty odd learning support tutors are here because it is quite an interesting job but it fits in with school terms and school hours.”

In addition, at the time of carrying out the fieldwork, many of the middle management and administrative staff requesting paperwork were perceived to be in much more secure positions with permanent contracts and full-time work (though this has now changed).

Melody, a tutor on non-qualifications courses, articulated this sense of inequality: "There are a lot of people employed to try to make us improve all the time [...]. And so they come and observe and they have to find something that you've got to improve on in order to justify their salaries, but they are safe and we are not safe. [...] Because they have full time jobs and job security, the distribution of power [...] puts me in a very tricky position all the time, and all the teachers, I think. [...] You just have to do what you're told, basically, there's no negotiating position." Such experiences of inequality and insecurity did not motivate staff to invest time and energy in mastering new paperwork demands.

In contrast, there was a very low turnover of staff at the nursery (unusually for the sector, in which there are often difficulties in recruiting and retaining workers, Rolfe et al. 2003, Carroll et al. 2009), and most staff experienced a high level of job security. Staff were paid relatively well, on the scale of the larger public sector employer of which the nursery was part, rather than against the norms for nursery staff in the area. Ongoing training was encouraged, with some staff pursuing degree-level national vocational qualifications (NVQ4s) in childcare and some gaining Early Years Professional Status, equivalent to a graduate level qualification, and others engaging in specialist training in areas such as yoga for preschoolers. From this perspective, personal investment in mastering the paperwork made a lot of sense.

\section{Decontextualised trainings}

The final aspect of integration I will mention here is the extent to which training for learning to complete the paperwork was integrated with everyday working activities. At the Early Years Centre, the initial training provided at the introduction of the Birth to Three framework was a day-long course held at a local conference centre. Nicola, an experienced nursery officer, recalled being faced with "all this new paperwork" on the course and responding "Oh, what do we do?" As Louise described it: "We all went onto training sessions and we're met with language that we didn't understand and phrases which were totally different and actually you thought oh my goodnight you know how are we going to do this, we really did. [...] Forms were presented and leaflets were presented and you know go away and learn this, well, it was pretty meaningless until it went into action [...] I just ended up in tears with all these lists and headings.”

Libby described the course to me in vague terms, as being a one day course which explained "how you should have areas in the room to cover different parts of the birth to three", and found the introduction of the new framework as "quite daunting”. Her description of the initial training seemed quite irrelevant to her description of how she actually developed confidence in using the system, through action and mutual support: "I think everyone was in 
the same boat so we all just sort of spoke about it and then just picked it up as we went along. Now, you can do an observation and without even looking at the cards know what it comes under and know what your future play and practical support is going to be." The achievement of 'ease' arises from doing in context, rather than from training alone.

Training is a different issue at the adult and community college. Training was delivered in various ways, predominantly through meetings of the programme area team. Training was also provided through the regular quality inspections described earlier which included examination of and discussion of paperwork, and where this was problematic, some time with a one-to-one mentor to assist the member of staff in developing their paperwork skills. This appears a more 'integrated' approach than the provision of a decontextualised training day. However, particularly in the broader context of insecure working conditions, this could be problematic. Melody, who had been inspected and whose paperwork was felt to need support, felt extremely threatened when she was observed by "somebody very senior in the College” who "didn't think much of” her paperwork and so, "she has actually given me 3 hours of compulsory monitoring - is it mentoring it's called?" She did not experience the mentoring process as helpful training, but saw it as a threat and felt her job was on the line, despite being very confident in her role as a teacher.

\section{Integration and commodification}

The significance of integration for successful mastery learning is predicted by work in situated learning. Brown, Collins and Duguid state that activity, concept and culture are interdependent, and that learning must involve all three. Knowledge is always shaped by and connected with the activity and environment within which it has been developed, with the nature of the environment contributing importantly to the 'indexical representations' of the activity developed through learning. So, where aspects of the specific activity and the broader environment do not cohere, for instance where the paperwork demands do not cohere with broader work activities, it is to be expected that mastery learning is less likely.

In relation to decontextualised training, Lave and Wenger identify very little explicit 'teaching' being involved in development of mastery through participation in a community of practice. Rather, learners learn by engaging in the practice of the community. They identify differences between pedagogy and participation, suggesting that teaching curricula typically limit the resources which are available for learning, and that verbal instruction does not teach how to engage in practice, but rather how to talk about practice. From this perspective, it makes sense that decontextualised training sessions seemed to be less effective in developing mastery of workplace literacies than engaging in them through community activity.

The situation in adult education of competing for multiple funding streams, from which the nursery management are broadly free, produces an un-integrated system of paperwork demands, with different tutors being faced with different requirements, and often repetitious demands. Decontextualised trainings are another example of commodified education, and the difference between the 'day trainings' 'delivered' and 'cascaded down' through the early years site and the way they learned to deal with paperwork in situated activity has been discussed above.

The most significant aspect of integration though that is influenced by processes of commodification is the clashes between people's purposes at work as they perceive them, and the paperwork they are expected to complete, which are often expressed in terms of wanting to prioritise immediate relational and processual aspects of teaching and learning, rather than 


\section{K. Tusting}

the production of written representations of these processes. Such clashes of purpose led to anger and disengagement from the paperwork. In this regard, Ball's (2005) description of the 'struggles for authenticity' associated with commodified education rings true for many of the research participants here.

\section{Conclusion: Situated learning, commodification and the mastery of workplace paperwork}

This paper has explored two sites of learning workplace literacies: an adult education college and an early years centre. There was a striking difference between the ways the research participants in the two sites discussed their paperwork. Participants at the early years centre were much more likely to use a 'mastery' discourse, where people 'got the hang of it', 'got into the swing of it', and could 'reel it off'. Participants at the adult education college were more likely to talk in terms of learning to manage or coping with their paperwork, more or less effectively, rather than displaying this sense of mastery.

The paper identified key differences between the two sites which could account for these differences. Three significant factors were identified: the resources for learning available in the sites (including time and space, mediating artefacts, and other people); the nature of change in the sites (one major change followed by, broadly, a period of stability and consolidation, as against constant incremental changes); and the extent to which paperwork was integrated (part of one or multiple systems; integrated with broader purposes of work; or integrated with people's professional identities). These site-specific factors changed the nature of learning which took place in the sites, with resources, integration and stability promoting more 'mastery' learning, and in contrast, fewer resources, less integration and more change being more likely to lead to 'constant coping'. Of course, other factors not directly related to the nature of these sites also shaped the learning processes, such as participants' educational backgrounds and personal histories. However as I have demonstrated in this paper there is enough commonality across the two groups of participants to suggest that the nature of the site of learning plays a significant role in shaping the processes of learning literacy practices which take place therein.

These distinctive characteristics of the sites, shaping the learning processes which take place, have been interpreted drawing on ideas about situated learning and commodification of education. Both sites are situated within processes of commodification as described in section 1 above, although to different extents. Both are subject to the introduction of curricular control, and increased prescription of the nature of interactions with students or children; the inspection of quality against external standards, both from within the organisation and through external inspection regimes, producing reifications representing performance and quality; and the use of auditing and managerial techniques to process these figures for purposes of comparison, competition, publicity and appraisal. However, to date, early years settings are free from requirements to compete for funding, or to produce accountability measures against targets through testing educational achievements. The particular (and unusual) nature of the early years site studied here, with staff having longterm job security and reasonably good pay, is also different from the adult and community college, where constant funding pressures have contributed to many of the staff working on temporary hourly insecure contracts (another aspect of commodification, where the workforce become treated as an expendable resource for production). The site which is more heavily influenced by these processes is the site where development of a sense of easy mastery of these workplace literacies - 'skilled knowledgeability' - is mitigated against by a 
range of factors, many of which can be directly related to these broader social processes of commodification.

\section{Acknowledgements}

The project reported here was funded by the Economic and Social Research Council (ESRC). I would like to thank all those who participated in the research, and two anonymous referees for very helpful feedback.

\section{Notes}

1. The end of award report is available as Tusting (2009).

2. See Tusting (2009) for more methodological detail.

3. The system has changed now, with the introduction of the integrated Early Years Foundation Stage for children of all ages in September 2008 (DCSF, 2008).

4. Taken from L.'s achievement book, dated 12/2/07. Parental permission given for use of this extract.

5. $\quad$ Pseudonyms are used for all staff referred to.

6. Interviews have been orthographically transcribed, with repetitions, fillers and backchannelings edited out, and punctuation inserted to support my own interpretation of the sense of the quotation.

\section{References}

Apple, M. W. 2005. Audit cultures, commodification, and class and race strategies in education. Policy Futures in Education, 3(4), 379-399.

Ball, S. J. 2005. The commodification of education in England: Towards a new form of social relations: keynote address. Paper presented at the Japan-UK Education Forum. Available online at http://wwwsoc.nii.ac.jp/juef/ac/2005/kyoto05.pdf.

Barton, D., \& K. Tusting (Eds). 2005. Beyond communities of practice: language, power and social context. Cambridge and New York: Cambridge University Press.

Brown, J. S., Collins, A., \& Duguid, P. 1989. Situated Cognition and the Culture of Learning. Educational Researcher 18: 32-42.

Carroll, M., M. Smith, G. Oliver, \& S. Sung. 2009. Recruitment and retention in front-line services: the case of childcare. Human Resource Management Journal 19(1): 5974.

Chouliaraki, L. and N. Fairclough. 1999. Discourse in late modernity: rethinking critical discourse analysis. Edinburgh: Edinburgh University Press.

Cuban, L. 2009. Hugging the middle: How teachers teach in an era of testing and accountability. New York: Teachers College Press. 
K. Tusting

DCSF 2008. Statutory framework for the Early Years Foundation Stage: Setting the standards for learning, development and care from birth to five. London: Department for Children, Schools and Families.

DfEE 2000. Curriculum guidance for the foundation stage. London: Department for Education and Employment.

DfEE 2001. Skills for Life: The national strategy for improving adult literacy and numeracy skills. London: Department for Education and Employment.

DfES 2002. Birth to Three matters: A framework to support children in their earliest years. London: Department for Education and Skills.

Fairclough, N. 2003. Analysing discourse: textual analysis for social research. London: Routledge.

Folinsbee, S. 2004. Paperwork as the lifeblood of quality. In M.E. Belfiore, T.A. Defoe, S. Folinsbee, J. Hunter and N. Jackson, Reading work: literacies in the new workplace, Mahwah, NJ: Lawrence Erlbaum Associates.

Gleeson, D., J. Davies, and E. Wheeler. 2005. On the making and taking of professionalism in the further education workplace. British Journal of Sociology of Education 26(4): 445-460.

Hamilton, M. 2009. Putting words in their mouths: the alignment of identities with system goals through the use of Individual Learning Plans. British Educational Research Journal 35(2): 221-242.

Hanushek, E.A. \& M. E. Raymond. 2005. Does school accountability lead to improved student performance? Journal of Policy Analysis and Management 24(2): 297-327.

Hutchins, E. 1995. Cognition in the wild. Cambridge, Mass. ; London: MIT Press.

Kirsh, D. 1995. The intelligent use of space. Artificial Intelligence 73: 31-68.

Lave, J. 1988. Cognition in practice: mind, mathematics and culture in everyday life. Cambridge: Cambridge University Press.

Lave, J. 1991. Situating learning in communities of practice. In L. B. Resnick, J. M. Levine and S. Teasley (Eds.), Perspectives on socially shared cognition. Washington DC: American Psychological Association.

Lave, J., and E. Wenger. 1991. Situated learning: legitimate peripheral participation. Cambridge: Cambridge University Press.

Lawrence, S., and U. Sharma. 2002. Commodification of Education and Academic LABOUR--Using the Balanced Scorecard in a University Setting. Critical Perspectives on Accounting 13(5-6): 661-677.

Lucas, N., H. Casey, \& M. Giannakaki. 2004. Skills for Life core curriculum training programmes 2001/03: characteristics of teacher participants. London: National Research and Development Centre for Adult Literacy and Numeracy (NRDC). 
Machin, S., and S. McNally. 2008. The literacy hour. Journal of Public Economics 92(5-6): 1441-1462.

Osborne, M. and K. Sankey. 2009. Non-vocational adult education and its professionals in the United Kingdom. European Journal of Education 44(2), 271-289.

Power, M. 1997. The audit society: rituals of verification. Oxford: Oxford University Press.

Rogoff, B., and J. Lave. 1984. Everyday cognition: its development in social context. Cambridge, Mass.and London: Harvard University Press.

Rolfe, H., H. Metcalf, T. Anderson and P. Meadows. 2003. Recruitment and retention of childcare, early years and playworkers: a research study. Nottingham: DfES / National Institute of Economic Social Research.

Scribner, S. and M. Cole. 1981. The psychology of literacy. Cambridge, Mass.and London: Harvard University Press.

Shain, F. and D. Gleeson. 1999. Under new management: changing conceptions of teacher professionalism and policy in the further education sector. Journal of Education Policy 14: 445-462.

Taubman, P.M. 2009. Teaching by numbers: Deconstructing the discourse of standards and accountability in education. London: Routledge.

Troman, G. 2000. Teacher stress in the low-trust society. British Journal of Sociology of Education 21(3): 331-353.

Tusting, K. 2009. Paperwork and pressure in educational workplaces: the textual mediation of target culture: Full Research Report ESRC End of Award Report, RES-000-222036. Swindon: ESRC.

Tusting, K. 2010. Eruptions of interruptions: managing tensions between writing and other tasks in a textualised childcare workplace. In D. Barton \& U. Papen (Eds.), The anthropology of writing: understanding textually mediated worlds (pp. 67-89). London and New York: Continuum.

Valli, L. and D. Buese. 2007. The changing roles of teachers in an era of high-stakes accountability. American Educational Research Journal 44(3): 519-558.

Wenger, E. 1998. Communities of practice: learning, meaning, and identity. Cambridge: Cambridge University Press.

Williams, J., B. Corbin and O. McNamara. 2007. Finding inquiry in discourses of audit and reform in primary schools. International Journal of Educational Research, 46(1-2): 57-67. 